\title{
A QUINTESSENCE OF SENSITIVITY: THE COFFEE LEAF-MINER
}

\author{
By George N. WolCOTt ${ }^{1}$
}

High humidity, with many rainy days, characterizes the climate of the lower mountainous slopes of tropical America where Arabian coffee, Coffea arabica L., grows. Even on sunny days, clouds often drift by overhead, their passing shadows inducing the sudden darting flight of numerous little satiny white moths, the adults of the coffee leaf-miner, Leucoptera coffeella Guérin-Méneville. When the sun reappears, fiight ceases as suddenly as it began, and the coffee grove that was alive with the flashes of their wings a minute ago now appears deserted of active insect life.

Despite their small size, they are quite conspicuous in flight, but when at rest they closely fold their silvery wings around their body. The sudden, positive manner in which these minute insects react to a variation in light intensity is characteristic of their reactions to other natural factors of their environment.

Humidity is decisive in determining in what parts of the grove heavy leaf-miner infestations will develop, altho to temperatures within the limits at which coffee thrives, the insects appear relatively insensitive. The female moths tend to oviposit mostly on wind-swept ridges where the evaporating power of the wind is greatest, and least at the bottom of ravines where the wind can not penetrate, and relative humidity remains high at all times. Climbing the slope, one finds all gradations in the amount of infestation, with the maximum always where the action of the wind is most marked. Porous-cup atmometers show this in the coffee grove, as does artificial rearing of the insect in separate compartments of a reenhouse of which the humidity can be controlled. There is the very best of reasons why the female moths should prefer the more exposed plants for oviposition, as during prolonged periods of rain the mines of the caterpillars in the coffee leaves become filled with water, in which the caterpillars drown. During such weather, it is

1 Head, Department of Entomology of the Agricultural Experiment Station, University. of Puerto Rico. 
in the exposed situations that the wind dries out the leaves most rapidly and it is here that the insect will have the best chance for survival. Indeed, it is on the single factor of humidity that most of the observed differences in abundance of leaf-miner depend.

The scarcity of the leaf-miner in Haiti, as compared with its abundance in Puerto Rico, is due to local methods of no cultivation, and allowing coffee trees to grow wherever volunleer plants had happened to sprout, making such a dense tangle of trees that humidity is always high, while soaring mountains often cut off all exposure to winds. New plantings in Haiti, with small trees widely spaced and open to the wind, invariably suffer heavy infestation just as they do in Puerto Rico. The scarcity approaching total absence of coffee leaf-miner in old Haitian groves is definitely not due to some new and more efficient larval parasite, for all collected in Haiti had previously been known from Puerto Rico, and Chrysocharis lividus Ashmead, reported by O. W. Barrett as long ago as 1905 and often the most abundant of any in Puerto Rico, does not occur in Haiti at all. Even proper wide spacing of the trees fails to provide a suitable environment for the leaf-miner in Trinidad, which is out of the trade wind and hurricane belt, and its coffee groves have maximum humidity in the ravines in the Northern Range of mountains.

Sensitive as the ovipositing female moth is to differences in humidity, apparently she does not distinguish between Arabian coffee with tender leaves suitable for the development of her young, and such a tough-leaved species as Coffea stenophylla Don. The minute caterpillar developing within a leafminer egg laid on such a tough leaf hatches normally, and without emerging from the protective covering of its egg-shell, eats thru it directly into the leaf tissue beneath. It attacks the tough leaf tissue with apparent success at first, but often by the second day all activity has ceased, and the little caterpillar is dead. Had the egg been laid on a leaf of Arabian coffee, the minute caterpillar would normally continue eating a cavity into the central tissue of the leaf until this is large enough so that it could crawl entirely out of the egg-shell. Like most kinds of insect larvae living in a protected situation, its flattened body is opalescent whitish, the head somewhat darker, with the sharp edges of its jaws almost black. It continues to eat and increase in size within its mine in the coffee leaf, feeding only 
on the most tender cells and avoiding those of both the upper and lower outside skins of the leaf.

Leaf-miner larvae attacking some other kinds of leaves are sometimes precipitated into the outer world during rainy weather, when the thin outer skin of the leaf they have attacked is rotted by rain. Those of even the most tender coffee leaf are of tougher texture and resist decomposition at least long enough for the caterpillar to complete its growth, but unfortunately are sufficiently permeable to rain-water so that it collects in the mine, distending it almost to bursting.

Drowning in its rain-water filled mine is not the only peril besetting the coffee leaf-miner caterpillar in its mine. Numerous kinds of minute parasitic wasps occur in coffee groves, which, with their minute sharp ovipositor, may puncture the skin of the mine and lay their egg on or within the body of the caterpillar. In Puerto Rico, Mr. Francisco Sein has reared ten kinds of these minute wasps which are either parasites or super-parasites on the coffee leaf-miner. Arranged approximately in the order of their abundance, their names, as determined by Mr. A. B. Gahan of the U. S. National Museum, are as follows:'

Closterocerus leucopus Ashmead

Chrysocharis lividus Ashmead

Horismenus cupreus Ashmead

Zagrammosoma sp. nov.

Closterocerus sp. near cinctipennis Ashmead

Cirrispiloideus sp. nov.

Derastenus sp. near fullawayi Crawford

Tetrastichus sp. nov.

Telenomus sp.

Microbracon sp. (det. C. F. W. Muesebeck)

In coffee groves near the coast and at no great elevation, some of these minute leaf-miner parasites are at times reasonably abundant, but at the higher elevations where most coffee is produced, they are far from numerous and usually are so scarce that all of them together rarely destroy more than an eighth or a tenth of all leaf-miner caterpillars. From the commercial standpoint, therefore, they are of negligible importance, and even the entomologist finds them so scarce that careful studies of each one, to determine its status and non-parasitic habits, are almost impossible. This list of parasites is longer from Puerto Rico than from the other Larger Antilles 
only because studies here have been more intensive, but the same or similar parasites occur in the coffee groves of all of these larger islands.

Quite different is the parasitic situation in the coffee-producing islands of the Lesser Antilles, for Mr. Seín discovered a previously undescribed parasite, later named Mirax insularis by C. F. W. Muesebeck, to be normally responsible for the destruction of sixty to eighty-five percent of all leaf-miner caterpillars in the island of Guadeloupe, F. W. I., and only slightly less effective in other adjacent islands. Introduced into Puerto Rico in 1937, it is unquestionably established in the mountains around Lares, but even when present in greatest abundance, attacks less than three percent of the leaf-miner caterpillars, and at most times only a small fraction of one percent will be found parasitized by Mirax. The desirability is obvious of the most careful comparative ecological study of the requirements of each and every parasite of the coffee leaf-miner in every island of the West Indies. The establishment in coffee groves of the optimum conditions for the development of some or most of these parasites may be impossible of practical attainment, but the factor lacking for one or several may be readily supplied, if we know what that factor is, and thus result in commercial leaf-miner control.

When fully-grown, the leaf-miner caterpillar is less than a quarter of an inch in length, smaller indeed than many other kinds of caterpillars just hatched from the egg. It acts like some of them also, in a most interesting way, for emerging from its mine when the wind is not blowing, it spins a long thread of silk with incredible swiftness as soon as a breeze begins to blow. If the breeze stiffens, the thread soon becomes so long as to be buoyant to the insignificant weight of the caterpillar, so that as soon as the thread breaks loose from attachment, the caterpillar may be carried far from the leaf from which it obtained its nourishment. This phenomenon can be most readily observed during a period of fitful breezes: the dropping of the caterpillars on their threads as soon as the breeze starts, and sudden halt when the breeze stops, followed by a prompt lengthening of the threads again as the breeze starts. If the breeze stops entirely, the caterpillar is left indefinitely suspended in mid-air, a ready prey to any passing reinita or warbler. 
Spinning of the cocoons may take place on any leaf, not necessarily of coffee, but of any plant that happens to be present in the grove. In the selection of a position for the cocoon, the caterpillar is sensitive to varying intensities of light, for in complete shade the cocoon may be formed on the upperside of a leaf. Normally, however, it is on the underside, the caterpillar first constructing a silken hammock under a slightly raised portion of the leaf, this support of white silk often taking the form of an $\mathrm{X}$. Upon this silken mattress the caterpillar spins the cocoon proper, within which it transforms to pupa. It remains as pupa three to nine days. The moth leaves the cocoon at night, mates, and often has completed oviposition by the next day.

Within the short span of its life-history, the leaf-miner both as adult and as caterpillar has shown itself very sensitive to variations in light intensity; as adult to humidity, and as caterpillar to air in motion. When as much is known about the reactions of each of the parasites of the leaf-miner to natural conditions in coffee groves as is known of their host, we may anticipate much more efficient natural control of this pest of coffee by its parasites.

January 8, 1943.

\section{Footnote:}

This summary of observations on the coffee leaf-miner made with and by Mr. Francisco Seín Jr., is published at the present time because of his departure from the Experiment Station, effective June 30, 1948, after continuous employment there since October 8, 1918. The original publication of most of these observations is scattered thru the reports of the Division of Entomology in the Annual Reports of the Experiment Station from shortly after that date almost up to the present.

George N. Wolcott. 